\title{
Chapter 2 \\ Extending the Limits I: Non-visual and Non-auditory Artworks
}

\begin{abstract}
We talk about culinary arts, as we also talk about martial arts. Does this mean that a meal or a kata are to be understood as being artworks? In this chapter, I take these and other cases seriously and I claim that they are indeed genuine cases of art, in the same way as paintings, photographs, sculptures, or musical works. My centre of interest concerns non-visual and non-auditory forms of art. Traditionally, visual and auditory arts dominate the debate in aesthetics and philosophy of art, as they dominate the art world in general — our senses of sight and hearing thus dominate our very understanding of what an artwork is. As a consequence, artworks are mostly understood as being public entities, widely shareable in the sense of being available to different spectators/auditors. In this chapter, I explore other senses, which are often neglected; I focus on gastronomic meals as cases of gustatory and olfactory artworks, and on dance, karate, and climbing as cases of proprioceptive artworks. The overall aim of this chapter is thus to extend the limits of what counts as art and what does not. I offer a very inclusive view, and through the discussion of various types of examples, I offer reasons to think that such a view is indeed adequate.
\end{abstract}

\subsection{Introduction}

$\S 1$. To start the discussion, let me indulge in a short biographical narrative and recount an experience I recently had in the restaurant of the famous French chef Marc Veyrat (in his restaurant La Maison des Bois in the mountains near Annecy). One of the meals on the menu consists in a small, greenish, olive-shaped and -sized, rather strangely looking 'thing' with an irregular surface, which does not look very palatable at all. It is prepared by the chef himself in the middle of the restaurant, for all guests at the same time, and it is 'cooked' in liquid nitrogen, piece by piece. When the chef gives it to your hand, it's very cold, it even burns a little, and it emits strange fumes. Once each guest has been given their own piece, the chef then asks everybody to close their eyes and to put the 'thing' in their mouths. Let me try to convey the gustatory and olfactory experience which follows: various textures succeed each other, the 'thing' being first solid, and then very suddenly liquid and gas at the same time, where both the liquid and the gas ingredients continue to evolve 
and transform, providing various stages of the overall experience. Each stage brings with itself a different taste and a different scent, ranging from wood, lichen, fir tree, pine cone, forest herbs,... to simply fresh air. The succession of the different stages provides an overall experience of smelling and tasting the forest itself - a gustatory and olfactory walk in a forest. And indeed, that's what the chef planned to provide as an experience for the guests, reinforcing the experience by telling a story aloud and by asking his guests to imagine, with their eyes always closed, that they are walking through the forest which is just behind the restaurant and where all the ingredients for this 'meal' have been collected. The succession of different tastes and odours is so skilfully done and planned that the illusion is very strong indeed and the overall experience simply staggering.

$\S 2$. We often talk about "culinary arts", and I am going to defend the view that this is a case where we can take the "arts" label seriously. I am also going to defend the broader view that many meals and drinks, including but not being exhausted by examples of gastronomic cuisine, give rise to olfactory and gustatory artworks. Perhaps this claim is not actually very controversial and perhaps some might even find it to be rather trivial. But traditionally, visual arts like painting or sculpture, as well as auditory (musical) arts, dominate the debate in aesthetics and philosophy of art, and they of course dominate the art world in general, occupying galleries and museums around the world. In this way, our senses of sight and hearing often dominate our very understanding of what an artwork is. This is one of the reasons why artworks are mostly understood as being public entities-shareable in the sense of being available to different spectators/auditors. (There are of course also other types of public artworks, like novels.) In this chapter, I am going to explore other senses, which are often neglected. I'll discuss the case of gustatory and olfactory artworks and the case of proprioceptive artworks (I'll focus on dance, karate, and rock climbing). The overall aim of this chapter is to push the limits of what counts as art and what does not. I'll offer an inclusive view, and through the discussion of various types of examples in this chapter I'll offer reasons to think that such a view is indeed adequate. (Chap. 3 will then push the limits even further.) Many human activities will thus, in my view, give rise to artworks (or simply be artworks) perhaps much more often than what is usually thought and accepted. To my mind, this is a good thing. I'll defend this general view and I am going to say why such a view does not lead to a situation where just 'anything counts' and where the notion of an artwork would become empty of any genuine meaning by being too broad and too inclusive. In this chapter, I'll focus on gustatory and olfactory artworks as well as on proprioceptive artworks; extending the limits concerning our sensory perceptual modalities. In the next chapter, I'll then focus on intellectual artworks; extending the limits to the domain of scientific and philosophical theories. 


\subsection{Gustatory and Olfactory Artworks}

$\S 1$. To start the discussion about gustatory and olfactory art, two caveats are needed.

First, it is not clear that the two senses, namely taste and smell, are really two. Indeed, it is perhaps more adequate to say that our perceptual system typically integrates information from both of these sensory modalities into a common multi-modal whole. Taste and smell often mingle together to produce an overall experience with these two aspects, which can be distinguished to some extent, but where the resulting whole is as important as their individual contributions. ${ }^{1}$ I thus suggest to talk here, for the sake of brevity, about gustatory experiences and about taste, but when I do so, I intend to fully include olfaction in the story. The sense of touch should also be included in this package, at least partly, since it allows us to feel the textures and the hardness or softness of the objects that we taste, which is highly relevant when it comes to the appreciation of their taste-typically, the way a taste is released and distributed (slowly, suddenly,...) in the mouth depends on the texture (soft, melting, hard, crunchy, ...) of what one is tasting, the texture being also related to the (continuously changing) temperature of the gustandum. Thus, many inter-related factors (and at least three senses) are involved in what I will often refer to, for the sake of brevity, as taste or as a gustatory experience.

Second, when it comes to meals, especially gastronomic meals, it is of course true that they are not only objects of gustatory appreciation, but of visual appreciation as well. Indeed, in a way that is perhaps not very controversial, gastronomic meals $q u a$ visually appreciated objects on a table can be understood as being artworks, in the same sense other visually accessible objects can be such (sculpture is perhaps the closest standard case). This is especially important since we typically first see what we eat before we eat it, which creates an amount of expectation from our part, and before we even taste anything we quite naturally imagine what it is going to taste like. This can have a strong influence on our gustatory appreciation, as many experiences involving green-coloured meat, blue-coloured strawberries, etc. have shown. Remember what the chef Marc Veyrat does when he presents his peculiar 'meal' to his guests: he asks everybody to close their eyes, and for a very good reason since this piece of food is visually not appealing at all, and since the whole point of the culinary experience is the gustatory aspect of it (again, including olfaction and touch as well). The point is to focus on the gustatory experience (to this end, it would perhaps be even better not to show the 'thing' to his guests at all.) This is of course familiar from blindfolded wine-tasting, and it is also the whole point of some popular restaurants where guests find themselves in a fully dark room and where they are thus deprived of their sense of sight. A trained evaluator of food or wine can often manage to free herself from any unwanted influences of the visual aspects of the object of her evaluation (while they are, often, actually wanted and judged to be relevant for the overall appreciation of a meal or a wine), and less-trained evaluators can simply try to do so, in order to isolate the gustatory aspect of their experience.

\footnotetext{
${ }^{1}$ See Korsmeyer (1999, p. 79-84).
} 
There are also other kinds of influences, wanted or not, that can have an impact on a gustatory experience. To mention again the case of Marc Veyrat, he not only asks his guests to close their eyes, but he also tells aloud, in the restaurant, a story about a walk in the nearby forest, thus reinforcing the overall experience of "tasting the forest". Indeed, what he does is that he uses his uncanny meal as an imaginationtriggering tool where the object he submits for gustatory appreciation to his guests prescribes imagining a specific narrative, which is then reinforced by the narrative that he explicitly voices aloud (I'll come back to this in section V below, where I'll make a comparison with Walton's similar view about depiction).

$\$ 2$. With all this in mind, can we say that there are gustatory artworks? Roger Scruton (who focuses on wine ${ }^{2}$ ) denies that there are because "[...] smells cannot be organized as sounds are organized: put them together and they mingle, losing their character [...] they remain free-floating and unrelated, unable to generate expectation, tension, harmony, suspension or release" (Scruton 2009, p. 122). But, we have just seen a striking counter-example to this, namely Marc Veyrat's peculiar meal. In this case, tastes (and smells and textures) are quite precisely orchestrated and provide an organized succession of individual gustatory experiences which constitute a coherent whole, which is not only surprising but also balanced, harmonious, unified, complex, and which provides intense gustatory pleasure to the appreciator. This is a particularly elaborated case. But even if in a perhaps less strong way, this applies perfectly well to wine as well, and-perhaps even quite trivially - this is also true of many meals, especially (but not only) gastronomic meals. The idea of balance and harmony on the one hand, and surprise on the other hand, and the idea that a meal should be a complex but unified whole which provides intensity and pleasure lies probably at the core of concern of any chef who takes her cooking at heart. ${ }^{3}$ We are here in a situation where the various typical features of artworks I mentioned in Chap. 1 (\$3-4) are quite clearly found. Such meals (or drinks), qua objects of taste, thus exhibit aesthetic properties based on these various features, and they can be evaluated, appreciated and judged to be of aesthetic value by any trained (or even less trained) evaluator. As it is the case with Marc Veyrat's guests, and as it is the case in many other situations of food tasting, wine tasting, and similar, the gustatorily accessible whole made of smells, textures, and tastes thus provides pleasure (or displeasure) which can be quite intense and trigger an emotional response, thus triggering a typical state in which we find ourselves when we appreciate the beauty of something. Thus, contra Scruton, it appears that the criteria (1)-(4) from Chap. $1(\$ 3)$ are in many cases of gustatory experiences fully satisfied and that such gustatory objects of appreciation can in this sense very well be understood as objects of aesthetic appreciation, where the successful (sufficiently developed) cases constitute cases of being artworks.

\footnotetext{
${ }^{2}$ For a critical discussion and a fully-developed view about wine, see Todd (2010).

3،[...] many meals are intended by their cooks to be considered largely in this way- to be savoured, appraised, thought about, discussed - any many eaters consider them in this way. Such meals also serve the functions of relieving hunger and providing nourishment, but they are of a kind which shows that this is not the main point of them." (Telfer 2008, p. 16).
} 
Criterion (5) (namely, the idea that artworks have the capacity to convey meanings and ideas) is perhaps less present in the case of gustatory artworks than, say, in the case of paintings, but it is present to some extent. As already mentioned, the whole point of the gustatory experience provided by Marc Veyrat is a kind of a gustatory walk in the forest, which conveys something like the concept of a Shinrin-yoku (森林浴—a 'forest bath'), which is all about the idea of connecting us to nature, to the forest, and which allows us to reflect on our often too urban lifestyles. Most meals do not have such a precise meaning, and perhaps many meals do not provide any clear meaning at all. This does not constitute an objection to the idea that there are gustatory artworks. First, because criterion (5) is not a necessary condition for being an artwork, it is simply something that many artworks provide. Second, because even if the idea conveyed by a gustatory artwork is merely a less sophisticated idea of harmony, balance, and pleasure, it is enough for us to aesthetically appreciate it. And third, the gustatory experience can trigger our imagination in such a way that as a reaction to it we can provide a further meaning-for instance, when tasting an exotic meal, the idea of where the ingredients come from, both culturally and geographically speaking, can arise.

Criterion (6) is about the idea that artworks are/should be challenging. This can be understood in many ways, and it is of course usually meant to apply to standard arts like music or painting. But one simple way in which it can be applied to the case of gustatory artworks is that discovering new tastes or new combinations of tastes can be challenging both in an immediate and intrinsic way, simply as a new gustatory sensation (where its various features such as balance, harmony, complexity, etc. play an important role), and also as a basis for cultural comparison and debate (which relates (6) to (5)) - a sharp, strong and stinky Bleu d'Auvergne cheese is quite typical of one cultural background; earthy and musky Fenugreek spices are typical of another; umami (うま味—'pleasant savoury taste') is typical of yet another, and so on. It is common nowadays, at least in developed countries around the world, to have easy access to any type of food and tastes, so we are not any more so easily surprised and challenged, but the first time we taste something new, or when we taste a new combination of tastes, we do (at least sometimes) have a challenging gustatory experience. When it comes to very sophisticated gastronomic meals, wines, or whiskeys, the whole point is sometimes (not always) to provide a novel, surprising and challenging experience to the appreciator.

Concerning (7) and (8), quite trivially, it is the case that food, again especially when it comes to elaborated meals, as well as wine or whiskey, requires tremendous skill to be produced (this is (7)), and that it is of course highly relevant also as a non-aesthetic object and has a non-aesthetic function-we do need to eat to stay alive, after all (this is (8)). Focusing on the gustatory (and olfactory) aspect of food, since this is the issue here, tastes and smells are of paramount importance when it comes to spot unhealthy or rotten food, for instance.

$\S 3$. Quite clearly, what precedes indicates that we may consider gustatory artworks as being genuine artworks indeed. There is of course the question about what kind of food provides a gustatory experience which counts as an artwork and which does not. The taste of a quickly, unskilfully, and badly made burger would hardly be such that 
it would give rise to a gustatory artwork. But this does not provide an objection to the claim that at least some gustatory experiences are artworks. The various features we have seen above, namely harmony, unity, balance, complexity, simplicity, intensity, passion, or pleasure, will be found in some gustatory experiences and not in others. The same is true of any other type of art-my 6-years-old son's drawings and Dalí's paintings do not exhibit the same amount of potential for being artworks either (which does not imply that a child's drawing cannot be an artwork). In section IV below, I'll come back to this general issue when I'll examine the claim that 'not anything counts' (that not everything turns out automatically to count as art in my rather inclusive view), and also that not everybody's taste provides a good ground for evaluation.

Before we get there, let us turn our attention, in the next section, to another type of non-visual and non-auditory artworks.

\subsection{Proprioceptive Artworks}

$\S 1$. Proprioception is an inner sense-the inner perception which provides us with information about the position, the posture, and movements of our body. While writing this book on my computer in my office, I am sitting on a chair and I know, via proprioception, where my legs are and in what position they are, without having to look at them. I don't always (actually, almost never, in this situation) think about the position or movements of my legs while I am writing this book, but the information is readily and immediately available.

I'll take here on board the idea that proprioception is a kind of perception (see O'Shaughnessy 1998; Fridland 2011; for a critical discussion see Gallagher 2003). The sense of sight and the sense of hearing give us the possibility of visual and auditory perception, and the sense of proprioception gives us the possibility of an inner perception of our bodies. It is a controversial matter to determine whether proprioception is a distinct sensory modality from the sense of touch or if both of these senses are somehow variants of one and the same perceptual modality. O'Shaughnessy (1998) argues that they are two distinct perceptual faculties, while Massin and Monnoyer (2003) defend the view that proprioception and touch are one and the same sensory modality. For my current purposes, it is not necessary to make a choice between these two options - the important thing here is that proprioception can be reasonably understood as a kind of perception. We have seen in the case of gustatory experiences that they actually involve not only taste but also olfaction and touch, constituting a complex multi-modal whole. Perhaps a similar claim can be made here: we can reasonably say that proprioception, even under the view according to which it is a distinct sensory modality from the sense of touch, is often supplemented and accompanied by the sense of touch. Plausibly, I know where my legs are and in what position they are not only via pure proprioception but also via the sensation of how they touch the floor and the chair on which I am sitting. Indeed, our body always encounters some kind of resistance from the external world, often sensed by touch, 
which provides information about its posture, position, and movement. So, either the sense of touch and the sense of proprioception are one and the same thing, or they are two different sensory modalities but they often combine into a complex whole which provides us with the relevant information. Both options are compatible with what I am going to say below about proprioceptive experiences and proprioceptive artworks, and for the sake of brevity (as in the case of gustatory artworks) and I am only going to use the label "proprioception", while keeping in mind that touch plays a role as well.

$\$ 2$. I am going to talk about three types of activities: dance, martial arts (especially kata), and climbing, but of course my purpose is not (only) to make a specific claim about these three activities, but to argue for the general claim that there are proprioceptive experiences which 'count' as artworks. [Other sport activities or even any other activities engaging in the relevant way with one own's body could provide other examples (Kilian Jornet, a Spanish professional runner and ski mountaineer, explicitly claims that running races are artworks. $\left.{ }^{4}\right)$ ] Before we start, two caveats are needed.

First (as we have also seen in the case of gustatory experiences), dance, karate, or climbing not only provide proprioceptive experiences, on which I'll focus here, but they also provide visually accessible objects/events of perception for viewers who can appreciate a ballet, a kata, or a climber's ascent from the third-person perspective. The case of dance is perhaps the most obviously and standardly such that it gives rise to a visually accessible artwork. The same can be said about kata (which are indeed very similar to choreographed dances), and perhaps more controversially about a climber's movements while climbing a route, but I am not going to discuss any of these cases since they are (when/if they are) cases of visual artworks. My focus will be on proprioception.

It is true that dancers watch themselves in mirrors, and so do martial arts practitioners, in order to improve and adjust their movements. Climbers, especially professional climbers, use video recordings to watch themselves climb and to analyse their movements from the (public) third-person perspective. Adam Ondra, arguably the best climber alive (who climbed in 2017 the world's first $5.15 \mathrm{~d} / 9 \mathrm{c}$ route Silence in Norway - the most difficult route in the world) uses motion capture technology-in the same way the movie character Gollum was created, Ondra climbs with a number of sensors on his body, and this then allows him to watch a computer generated 3D model of himself climbing, and to analyse his movements in fine detail (see Bocek et al. 2018). But skilled dancers, karateka, as well as climbers rely most of all on proprioception to know whether a movement or a posture is correct or not. Mirrors, video recordings, and computer models can help, but a good practitioner will only use them as additional, secondary tools. The experienced practitioner will mostly appeal to her proprioceptive experience to adjust her movements/posture and improve her skills. (This is less true in the case of novices, who first have to learn before being able to rely on their proprioceptive experiences.) This is why (again, similarly to

\footnotetext{
${ }^{4}$ Kilian Jornet, "Run or Die: The Inspirational Memoir of the World's Greatest Ultra-Runner", VeloPress.
} 
what we have seen in the case of gustatory experiences), in a way that goes in the other direction than the use of mirrors or recordings, advanced practitioners would sometimes train blindfolded, in order to rely only on proprioception and touch to do what they are doing. (This is more common in martial arts, but some climbers also do train blindfolded in the secure environment of an indoor climbing wall.) Depriving themselves of the sense of vision, which is so crucially important that it tends to occupy the largest part of their normal conscious experience, they can then focus better on the properly proprioceptive experience and learn how to better exploit it. Marc Veyrat asks his guests to taste his meal blindfolded to highlight the gustatory experience, and the idea is here the same when it comes to proprioception. ${ }^{5}$

In short, in the case of dance, kata, or climbing, we have a public performance, visually accessible by viewers from the third-person perspective, but there also is a private proprioceptive experience of the dancer, karateka, or climber; an experience which is only accessible to the one who is doing the performance. The view I want to defend concerns the latter, and I will claim that it can give rise to proprioceptive artworks.

A second introductory point to keep in mind concerns the fact that, as O’Shaughnessy $(1998, \S 1)$ puts it, “[proprioception] takes a back seat in consciousness almost all the time". This is true: as mentioned before, most of the time, I am not actively proprioceiving the position of my legs while I am writing this book. Thus, a first requirement for there to be a proprioceptive artwork is that the relevant proprioceptive experience must (of course) be conscious and must (importantly) be focused on. This is why dance, kata, and climbing are such useful and good examples-indeed, practitioners of these activities are typically invited, by the very nature of what they are doing (at least, if they are doing it right), to focus on their proprioceptive experience. They need to pay attention to their proprioception. This is what O’Shaughnessy (1998, §2.a.1) refers to as "introspective proprioception”, where our bodily position, posture, and movement are the focal point of our attention. Some sport activities are about being quick and about reacting and executing movements in such a quick way that they need to be almost automatic. While such 'automated' movements can also sometimes be found in martial arts, dance, or climbing, more often than not practitioners of these activities have the luxury of taking their time to consciously and in a very focused way execute their movements. Climbers often pause between movements and think about the next hard movement before going for it, this is fully part of what climbing is about. Thus, they focus on the contraction of their muscles, on the very precise way their body is positioned at the moment and they very carefully imagine what the next movement must be and in what position

\footnotetext{
${ }^{5}$ I am not going to explore here the possibility that sexual activity can also provide proprioceptive experiences that could be artworks. But I do not see, prima facie, a principled obstacle to such a claim. Note that a blindfolded sexual experience (or an experience taking place in a fully dark environment) is appreciated by some practitioners, precisely in order to allow proprioception and touch to play the central role in their experience, without the influence of visual elements. Note what Schrenk (2014, p. 112) says about sex-work: "Would, for example, a sex-worker's performance on one's body, where intense proprioception is secured, be art? [...] If however, such meaning can be given to the sexual acts [...] there is probably no reason why sex-work could not become an art".
} 
their body will be after that next movement, before they actually do it- the harder the route, the more this is the case. Perhaps climbing is one of the best examples of this, and perhaps even more so than kata or choreographed dances where a larger amount of automatic execution is often required, in order to guarantee speed and fluidity. As it happens, climbers tend to focus and to consciously pay attention to their movements at all times (except if the route is easy and does not require to focus so much). This is also due to the fact that dancers and karateka often repeat the very same sequences of movements_-involved in the same kata or the same dancewhile climbers, once they successfully climbed a given route, typically move on to try another one and as a consequence they cannot 'automatically' repeat the same (sequences of) learned and repeatedly practiced movements ('speed climbing' is an infamous counter-example-often discarded by rock climbers as not really being proper climbing at all, partly precisely for the reasons I just mentioned). Paying attention is important, otherwise the aesthetic experience of one's proprioceptive experience is lost. The same is true in the case of gustatory experiences as well: even the very best of gastronomic meals can fail to give rise to a gustatory artwork if is it quickly eaten while watching TV and if the one who eats it simply does not pay attention to what it tastes like.

$\S 3$. One of the very best climbers alive, Chris Sharma, says that climbing is like dance on the rock: "Climbing is an artistic, creative thing.[...] Climbing is a fullbody sport from your fingers to your toes, but at the same time, it's like a dance on the rock. It's about being strong and fit but also graceful and elegant and efficient on the rock.[...] It's not just about being super strong." ${ }^{6}$ For Sharma, as a skilled practitioner, as well as for most rock climbers, it is just obvious that climbing is not only about strength but-very importantly_about elegance and beauty. Adam Ondra's climbing training for the next Olympic Games in Tokyo 2020 does actually involve ballet dancing - precisely and explicitly to work on the elegance of his body movements. ${ }^{7}$ This is why I am going to focus on rock climbing as being a good example of an activity which can give rise to proprioceptive artworks. But I do not mean to claim that there is something special about climbing here. Schrenk (2014) explores this claim in detail when it comes to martial arts, and I'll mention some useful points of comparison below. Barbara Montero argues for the possibility of proprioceptive artworks when it comes to dance: "proprioception is an aesthetic sense and [...] one can make aesthetic judgements based on proprioceptive experience.[...] One can deem a certain movement beautiful based on one's proprioceptive experience of the movement.[...] athletes, models, and perhaps even those with natural grace, may sense the beauty of their movements proprioceptively but the proprioceptive aesthetic sensibility of the dancer is perhaps the most pronounced." (Montero 2006, p. 231). This is one of the reasons why, according to Montero, the best evaluators of the aesthetic properties of a dance are people who are dancers themselves and who can imaginatively 'share' the proprioceptive experience of the one who is dancing. In my view, Montero is basically right except perhaps for the very last point in the citation

\footnotetext{
${ }^{6}$ Interview by Morty Ain for 'ESPN, The Magazine', July 2013.

${ }^{7}$ See Ondra's Youtube video: https://youtu.be/OKfE2ONpO20.
} 
above, since in my view the aesthetic sensibility of climbers or karateka is also very high. Sharma says that climbing is like dance on the rock, and it is easy to see how $k a t a$ are similar to choreographed dances-in this way, we find similar elements and similar types of proprioceptive experiences in all of these three activities. Relevantly to the purposes of the discussion here, all three activities exhibit the aspects and features that are significant for the claim that there can be proprioceptive artworks. Let us, then, focus on climbing in some more detail.

$\S 4$. As an outsider to the world of rock climbing, one might think that climbing is about getting to the top of a mountain or a rock wall. Perhaps this is so because there is some amount of vagueness surrounding alpinism, Himalayan expeditions, and rock climbing — and because, after all, these all often involve climbing mountains where a successful practitioner does often get to the top of some summit. I am going to leave alpinism and mountain climbing aside, and only focus on what is often referred to as "rock climbing" or "sport climbing". Rock climbing is not so much about getting to the top of something, it is about sequences of perfect movements. Take a common situation: a rock climber tries for the first time a route and finds it utterly impossible to climb. Perhaps, she manages to climb some sections, but as a whole the route appears to be too difficult. She just does not see what to do in order to connect the dots and make a successful ascent without falling or stopping. Sometimes, a particular movement just requires more strength than what she has. But often, the failure or success is not just a matter of sheer strength. Even a climber strong enough to climb a given route might be puzzled by it at first. Indeed, climbing routes are puzzles - for the body and for the mind. As Nguyen (2017) puts it, climbing is a "hyper-intellectual" sport. In order to successfully complete a given route, one needs to 'solve' it-and, importantly, one needs to solve it with one's own body as well as one's imagination. A climber needs to try, again and again, in order to feel and find the precise position of all ${ }^{8}$ parts of her body, her body weight distribution, the parsimoniously applied amount of required strength (while keeping strength for the remaining part of the route), as well as the order in which the holds need to be grasped in a very precise and carefully balanced manner. Once such a sequence of subtle and refined movements is found, all there is to do is to execute it; but this is the less interesting part of the job and it is-usually-less difficult than the process that lead to the personal discovery of how the route should be climbed. In many climbers' experience, once the puzzle has been solved, the route that seemed impossible at first becomes actually rather easy to climb-sometimes, it is surprising how something impossible becomes so easy to do. Thus, rock climbing is all about finding a harmony between oneself and the route. Once this harmony is found, as Nguyen (2017) nicely says, "you dance your way up that wall". Indeed, this is the very point of rock climbing - again, it's not about getting to the top of a mountain or a wall, and not just because there are usually much easier ways to get to the top anyway, but importantly because a climber typically does not want to complete a

\footnotetext{
${ }^{8}$ Including even the head. Adam Ondra is known to have a long neck, which allows him to use the weight of his head to counterbalance the weight of other parts of his body, when he climbs particularly difficult routes.
} 
route and arrive to the top just by applying brute strength, but rather by finding the best, most elegant, and most economical way to execute the required sequence of movements to finish the route in a 'clean' and balanced way.

Thus, as a proprioceptive affair, rock climbing is full of aesthetic experiences. We find here, quite obviously and strongly, all of the common features of aesthetic experiences mentioned earlier such as harmony, symmetry, unity, passion, pleasure, balance, intensity, complexity, simplicity, and elegance. A climber's movement can be awkward and can only succeed by applying sheer strength, but as I emphasized above, a climber will not be happy with such a success-she'll be after a movement that feels right: grace must combine with power to provide a feeling of a precise and economical movement, executed with simplicity and elegance. Such a movement is often both simple and incredibly complex: it is simple because it proprioceptively feels so once it is mastered and gracefully, fluidly performed; and it is complex because it often involves many micro-movements and individual position adjustments of all parts of the climber's body, in very much detail. This is why it can take a long time before a climber 'solves' a particular section of a difficult route, since it requires many, many attempts. ${ }^{9}$

This kind of activity requires the practitioner to focus in a very strong way on her proprioceptive experience-otherwise, quite simply, it will just not work. Many climbers report that while they climb they manage to be incredibly intensely focused just on what they are doing and proprioceiving. ${ }^{10}$ As Nguyen (2017) puts it: "Some of the most focused and attentive I've ever been in my life is on a hard climbmind zeroed in on tiny ripples in the rock for my feet, exactly the angle of my ankle, whether I'm holding the most grippy part of the rock with my hand, the exact level of force I need to push with on my foot as I slide over to the next hold." This is, indeed, the perfect case of what O'Shaughnessy $(1998, \S 2 . a .1)$ refers to as "introspective proprioception". In a very focused way, climbers are then conscious of their own movements, as well as the posture and position of their body, in great detail and in a very demanding way, and the aesthetic experience they are having then arises from their proprioceptive experience. A climber's movements (and complex sequences of movements) just have to be balanced, harmonious, unified, simple and complex, economical and gracefully fluid-otherwise, she will just not succeed to complete a difficult route. Thus, the very nature of rock climbing is such that, when done in a correct way, it actually forces the practitioners to have a proprioceptive aesthetic experience. This is then where the intense pleasure and passion of most climbers comes from.

$\S 5$. Let us now consider the list of criteria we have seen in Chap. 1 (\$3-4) for something to be an artwork, and let us see how they apply to proprioceptive experiences such as those we can find in rock climbing, martial arts, and dance. We

\footnotetext{
${ }^{9}$ Tommy Caldwell and Kevin Jorgeson's first ascent of the most difficult multi-pitch route in the world "Dawn Wall" (5.14d/9a, 32 pitches, El Capitan, Yosemite) provides an excellent illustration of this. (See the documentary film "Dawn Wall" (2017) about this ascent).

${ }^{10}$ Alex Honnold's free solo (i.e. without a rope) ascent of "Freerider" $(5.12 \mathrm{~d} / 7 \mathrm{c}, 900 \mathrm{~m}$, El Capitan, Yosemite, 6/3/2017) is a staggering example of focusing capability. (See the documentary film "Free solo" (2018) about this ascent).
} 
have already seen that, qua proprioceptive experiences, climbs possess many of the standard features artworks typically have. We have seen that the very nature of rock climbing is such that it actually forces the practitioner to focus on her proprioceptive experience and that it also forces her-if she wants to successfully climb a difficult route- to have aesthetic experiences. Indeed, the proprioceptive aesthetic experience - in short, the elegance of a movement—will help the climber to climb better. Points (1) and (3) are thus quite obviously satisfied, as is point (4)—indeed, the emotional response to the experience of oneself climbing is often strong, both when things work in the perfect and elegant way they should, where the sheer joy of feeling oneself climbing fluidly and well is significant, as well as when, exasperatingly, things do not work. Many climbers would shout aloud in strong frustration when they fall, especially if they do not understand what it is exactly that they are doing wrong - that is, in a situation in which they did not yet solve the puzzle of a given route. Adam Ondra is quite known to shout very loudly when he falls, using some very strong language (fortunately, to be understood only by the Czechs).

(1), (3) and (4) are also commonplace in the case of martial arts and in the case of dance. Proprioceptive experiences of kata and of dance also importantly involve movements that aim at being balanced, harmonious, unified, both simple and complex, as well as economical and gracefully fluid. It is also true, in both of these cases, that the very nature of these activities is such that it requires the practitioner to focus on her proprioceptive experience, and that this aesthetic proprioceptive experience is a good guide to doing things right. When it comes to martial arts, Schrenk (2014, p. 112) makes a comparison with 'standard' visual and auditory arts and he even claims that the former probably satisfy criterion (4) better than the latter: "While many auditory and visual arts affect the intellect more than the emotions (or, at least, emotions only mediated through the intellect), a proprioceptive art would be directly in touch with one's feelings." Indeed, when immersed in a proprioceptive experience, one does feel very strongly and immediately her own body and the emotions associated with what is going on.

Of course, not only do climbers, karateka, or dancers have aesthetic proprioceptive experiences and strong emotions associated with them, but they also, often and passionately, talk about them, articulating aesthetic judgements about what they are doing. When it comes to climbing movements, the word "elegant" is perhaps the most often pronounced, as well as the word "beautiful". Adam Ondra comments on his climbing of "Robin Ud" (9b/5.15b): "The beauty of movement is very important for me. Very often I can find it on some rocks that a lot of people would think of as very crappy. But the beauty of movement is there [...]." ${ }^{11}$ As we have seen above, these are not metaphorical uses of this vocabulary; rather, the fact that aesthetic judgements about a climb are so natural and so common points to the fact that they are indeed understood as such by skilled practitioners. (Remember Sharma's explicit claim above that "climbing is an artistic, creative thing".) Thus, point (2) in the list of criteria from Chap. 1 is also satisfied, and of course not only when it comes to climbing but when it comes to dance and kata as well.

\footnotetext{
${ }^{11}$ Adam Ondra's first ascent of "Robin Ud": https://www.youtube.com/watch?v=gbK4MqpFsVc.
} 
Point (5) is perhaps less clear-cut. Do climbs, kata, or dances, qua proprioceptive experiences, have the capacity to convey meanings and ideas? We must be careful here not to mix up ideas and meanings that can be conveyed by the activity as such, and the ideas and meanings that can be conveyed by the activity as a proprioceptive experience. Indeed, it is uncontroversial that climbing involves many values and ideas-perhaps, to cite only one, a sense of trust and friendship, since a climber's life quite literally depends on the skills of the other climber who is belaying her. In the case of karate, many of the values associated with it even lie quite outside the scope of the activity as a combat technique-indeed, "karate" means “empty hand" (空手) and is often supplemented by “dō" (道) which means "path" or "way"; the idea being here that karate-do is not merely a fighting system but that it also is a spiritual system: the way of the empty hand. But such ideas and meanings are not directly linked to the proprioceptive experience of climbing or of performing a kata. Rather, they are overall ideas concerning these activities. Ideas and meanings exhibited by the proprioceptive experiences of climbers, karateka, or dancers are linked to the feelings of one's own body. They can involve ideas of health, fitness, 'feeling good in one's body', harmony between one's body and one's mind, and they can perhaps convey values such as perseverance and effort, since when a practitioner succeeds in performing a perfect sequence of graceful and powerful movements, all the hard training suddenly comes together and makes sense. Most of all, the ideas involved in such proprioceptive experiences are, more directly, the ideas of balance, harmony, unity, elegance, simplicity, and efficiency.

Point (8) is about the fact that artworks can also be objects which have relevant non-aesthetic features and a non-aesthetic function. Here again, we must be careful to distinguish between such features that climbing, karate, or dance possess as human activities and the features they possess qua proprioceptive experiences. Indeed, karate is a fighting technique, whose practical use is one of the very reasons for its existence, while climbing does of course have the practical use to, say, get to the top of a mountain. Both disciplines, and of course dance as well, can also be appreciated as sport activities, improving one's health and fitness. But again, this is not related directly to the proprioceptive experience had by the practitioners. The practical usefulness of the proprioceptive experience is something we have already seen above: it helps the practitioners to climb, dance, or perform a kata better. The proprioceptive experience is indeed one of the best guides to performing the perfect movement and sequences of movements. As already noted, this is particularly interesting since it is the aesthetic aspect of the proprioceptive experience - the elegance, balance, harmony, unity, etc. of the movements - that helps the practitioner to improve her skills. This, then, also relates to point (7), namely the idea that artworks require skill to be produced, which is here quite obviously the case, since in order to be able to have a proprioceptive experience which exhibits the aesthetic features of beauty, elegance, harmony, etc., long and hard training is required. The challenging aspect (point (6)) of such aesthetic proprioceptive experiences lies then in the fact that they encourage and stimulate the practitioner - the artist - to do better and better. Indeed, these experiences are such that they provide the standard by which success or failure are measured, where here again it is their aesthetic properties that allow one to say whether one has succeeded or 
not - a climber, a karateka, or a dancer would not be entirely happy with a sequence of movements which would look right from the third-person point of view (and which would, say, successfully get her to the top of a mountain) but which would not 'feel right' and graceful/elegant from the introspectively proprioceptive private first-person point of view.

\subsection{Training, Skill, and Evaluation}

$\S 1$. Let us quickly sum up where we are. I have started in Chap. 1 by listing some criteria for something to be an artwork, while pointing to the fact that they do not constitute necessary and sufficient conditions and that they do not provide a strict definition of what an artwork is. Both when it comes to gustatory experiences and to proprioceptive experiences, I have then provided study cases which satisfy these criteria. As a consequence, we can then rather safely conclude that they qualify as being artworks.

$\S 2$. In this sense, I thus offer here a very inclusive view about what counts as art and what does not (in Chap. 3, I'll extend it even further). I take this to be a welcome output - the good news that we can produce and enjoy art more broadly than what one would perhaps have thought. But this does not mean that 'anything goes', that anything is an artwork; let us now consider some constraints as to what counts as an artwork as well as constraints concerning the evaluation of artworks.

When it comes to martial arts, Schrenk (2014, p. 108) puts the point nicely: "If you 'play' your body well, like a musician plays a sonata on her instrument, you have 'harmonious' proprioceptions. Many factors, including precision, speed, the appropriate kinetics and mental and physical fortitude have to be in proper control: not any performance will lead to something aesthetic and it takes the practitioner a long stony way under the austere guidance of their master to learn the right movements with the correct intrinsic dynamics. Yet, again, just as a violinist hears when his performance is right the martial artist will, with enough practice, herself feel when her movements are correct. As with sonatas, it is then that proprioceptive pleasure is greatest." Schrenk is right, as we have also already seen in III. 55 above with respect to criterion (7), concerning climbing, karate, and dance. Schrenk's formulation'playing one's body' - nicely sums up the idea that exactly as it takes time and effort to master a musical instrument, it takes time and effort to master one's own body to be able to produce movements that are both efficient and graceful-and it is only then that an appropriately aesthetic proprioceptive experience can take place, giving rise to a proprioceptive artwork.

The same is true when it comes to gustatory artworks. Marc Veyrat's peculiar meal is an example of tremendous skill and a result of great effort and training. A lot of things need to come together and need to be done well in order to provide such a gustatory experience to the guests of his restaurant. This is, of course, true of many well-done and carefully prepared meals, gastronomic or not. More often than not, the greater the skill and effort, the better and stronger the aesthetic gustatory experience. 
Granted, there are exceptions and interesting borderline cases. This is one of the reasons why I suggested in Chap. 1 that there can be nothing like a strict definition of what counts as art and what does not. Indeed, it is sometimes the very point of an artwork to question where the limits of art lie-and to explicitly cross them. Well-known, now standard, cases include Marcel Duchamp's ready-mades, which are ordinary objects put on display, such as his "Fountain" (1917). Another striking well-known example is John Cage's composition "4'33" (1952) which consists of three movements:

First movement—silence (00:00-00:30).

Second movement-silence $(00: 31-02: 53)$.

Third movement-silence $(02: 54-04: 33)$.

Are there similar cases when it comes to gustatory and proprioceptive artworks? Could there be a kata where the karateka would simply stand still for, say, 4 min and $33 \mathrm{~s}$ ? On the one hand, we could think that such a performance would hardly count as a karate performance at all, since the point of a kata is to be an imaginary combat-a combat against imaginary opponents. Not moving at all might not be the best fighting technique to overcome attacking adversaries. On the other hand, such a performance might actually provide a valuable proprioceptive (and introspective) experience, as many meditation techniques have shown (Zazen is a well-known example). This proprioceptive experience might then exhibit aesthetic features and might be subject to aesthetic appreciation, and thus count as an artwork, even if perhaps only in the way in which a borderline case might count as such. When listening to his " 4 '33", Cage wants us to pay attention to the silence, and to the noises there always aresilence is actually, under normal conditions, never complete. The same could be said of the karateka who is standing still-concentrating on her stillness, she might notice all of the unavoidable, small and usually imperceptible movements of her body.

When it comes to borderline examples of gastronomic meals, Marc Veyrat provides, here again, a striking example: another of his meals on the menu consists in an empty plate. It's quite a puzzling situation for a guest to be presented with a small, white, simple, empty plate. Marc Veyrat then sits down at the table with the guest and tells her a story about how, when he was young, in order to have less work and save water when doing the dishes, in his family they would use plates from both sides-first, the regular side for the main meal, and then they would return the plate and use its bottom to eat desert. After telling this story, he then returns the empty plate, and the guest discovers that in the small hollow space on the bottom of the plate is a skilfully integrated crème brûlée. Thus, in the end, the plate is not empty after all, and so the situation is here not directly comparable to Cage's " 4 '33". But at first, during the first stage of the process, the guest does have a type of a gustatory experience 'of nothing', given the empty plate and given the fact that she is at first led to believe that there is nothing more to it that just the empty plate. This might then be understood as an equivalently borderline experience to the listening to Cage's composition. One might understand the absence of a gustatory experience as a gustatory experience of an absence-indeed, after having tasted and eaten a dozen spectacular gastronomic meals, the guest is suddenly presented with only the taste of his own empty mouth, which does have a taste that we usually do not notice, and 
Veyrat's empty plate might precisely provide us with an experience where we focus on it (similarly as Cage's composition makes the listener focus on the silence, which is usually never entirely devoid of any sound either).

Such cases explore the limits of what can be acceptable as being an artwork or not, but the point is not different, as we have seen, in cases of gustatory or proprioceptive artworks and cases of more standard (although borderline) visual or auditory artworks. In my view, there is no strong reason to exclude such cases (Duchamp's "Fountain", Cage's "4'33", Veyrat's empty plate, a karateka's performance of standing still); they can count as being interesting borderline cases of (visual, auditory, gustatory, proprioceptive) art. But the main point I would like to emphasize is that they all fall or stand together: if, say, we accept Cage's composition as being an auditory artwork, we should then accept all the other cases, and vice versa.

$\S 3$. To conclude this section, some remarks concerning the evaluation of artworks is in order. To start, it is important to keep in mind that the evaluator's competence and skill play an important role. Indeed, exactly as not any proprioceptive or gustatory experience is an artwork, not everybody is a good evaluator of such pieces of art. This is why the aesthetic judgements involved in criterion (2) from Chap. 1 must always be judgements of skilled and experienced practitioners. When it comes to climbing, this is utterly obvious: in order to be able to see the beauty, elegance, grace, fluidity, and efficiency of one's movements while having the proprioceptive experience of climbing, one needs to have enough experience to be able to compare this experience to previous experiences and one-quite straightforwardly—needs to be skilled and strong enough to be able to perform the movements in the first place. Easy climbing routes usually do not require any particularly elegant movements; beginner's routes would be no harder than climbing a somewhat complicated ladder. The more technical a route gets, the more it will require movements that are precise, and that need to be elegantly and harmoniously combined to produce sequences of movements such that the climber will be able to successfully climb the given route. In short, a novice will simply not be able to execute the movements that are required to provide a sufficiently complex and rich proprioceptive experience to give rise to a proprioceptive artwork. The very same is true when it comes to martial arts, and dance as well. Of course, in some situations, some amount of elegance and proprioceptive beauty can be achieved without too much skill, but usually it will be true that the more a practitioner is skilled the more she will be able to create a proprioceptive experience that will be an artwork - in virtue of exhibiting harmony, symmetry, unity, balance, complexity, simplicity, intensity, passion, pleasure. Thus, criterion (2) from Chap. 1 is perhaps even more important when it comes to proprioceptive artworks than when it comes to visual and auditory artworks, which are more easily accessible to an unexperienced spectator. Indeed, in the case of proprioceptive artworks, the spectator also needs to be the artist, which means that the spectator needs to be skilled enough not only to appreciate the work of art, but also to create it. (I'll say more about the private aspect of such artworks in the next section below.)

In addition to her skill and experience, the evaluator's aesthetic taste also plays an important role. In the case of climbing, a skilled climber will often have a preference 
for some types of routes, requiring some types of movements. Some climbers will prefer strongly overhanging cliffs requiring a lot of work with the managing of one's own strength (economy and fluidity are here crucially important), as well as a number of acrobatic moves where one sometimes needs to place one's feet higher than one's hands, etc. Other climbers will prefer vertical routes with very tiny holds, where the key notions will be precision and balance. In the evaluation of the aesthetic proprioceptive experience, a climber's capacity and personal taste will thus play a central role when she'll make an aesthetic judgement about a route. But the notion of taste here is not just one of a mere liking. As Sibley puts it: "When I speak of taste [...], I shall not be dealing with questions which center upon expressions like 'a matter of taste' (meaning, roughly, a matter of personal preference or liking). It is with an ability to notice or discern things that I am concerned." (Sibley 1959, p. 423; see also Telfer 2008, p. 13) This is quite clear in the case of gustatory artworks, where experts would often evaluate a meal positively even when it does not fit their own personal preferences. Such 'taste' is indeed trainable and more objective than a simple liking. An expert will learn to distinguish different flavours, fragrances, and so on. Experts-both when it comes to gustatory experiences as well when it comes to proprioceptive experiences-will also often share standards by which they can evaluate the gustandum or the proprioceptive experience. The capacity to discern beauty of such trained and experienced experts will thus be higher than the capacity of a novice, whose taste will be closer to a mere liking. This, of course, echoes Hume's (1757) claim that not everybody's taste counts and that not everybody can play the role of a good art critic. Not surprisingly, experienced karateka, experienced climbers, and good chefs will thus often agree on the aesthetic properties of a proprioceptive/gustatory experience, and will evaluate the resulting proprioceptive/gustatory artworks accordingly. Of course, such artworks are private and cannot be shared directly; as a consequence, they cannot be evaluated directly by more than one evaluator. But this does not mean that any comparison is impossible, it only means that the evaluators must keep in mind the private aspect of such pieces of art, and use indirect means to compare their respective experiences-quite simply, by talking about them.

\section{5 'Private Versus Public'—Some Remarks}

$\S 1$. Excluding gustatory and proprioceptive experiences such as those we have seen above as being artworks on the ground that they are accessible only to the one and only subject who has them - that is, that they are private rather than public-would be question-begging. Indeed, it is often distinguished between on the one hand an artwork and on the other hand the experience that an artwork triggers (see the rather standard criterion (3) on the list in Chap. 1), but here, in the case of proprioceptive and gustatory artworks, the private experience is the artwork itself, making this case special in this sense. But even if this does not prevent such experiences to be artworks, their privateness is quite a striking feature, as opposed to more standard, public, 
visual or auditory artworks, which invites now some remarks on the 'private/public' distinction.

$\S 2$. From the experiential proprioceptive/gustatory point of view, two subjects can have the same type of experience but never, of course, the same token. Two karateka can perform the same kata, two climbers can climb the same route, two dancers can perform the same choreographed dance, and two guests at Marc Veyrat's restaurant can taste the same meals. But of course, the private aspect of such experiences is central to them, as Barbara Montero clearly puts it when it comes to dance: "It is not merely that the proprioceptive experience seems private since, arguably, there is a sense in which all experience is private. Rather, it is that the object of experience appears to be private: the object of visual experience, a painting, can be experienced visually by many observers, while the object of proprioceptive experience, one's own body, can be proprioceived only by oneself" (Montero 2006, p. 234). When it comes to climbing, Karlsen (2010) rightly remarks that the appreciation of the public performance-watching a climber's performance-is not sufficient in order to be able to appreciate the aesthetic aspect of climbing. We need to "include the experiential aspect of a climb" (Karlsen 2010, p. 221), since "a route being at the limit of one's skills is a criterion that [...] is valid for most climbers" (p. 222). The experiential, private aspect of proprioceptive experiences is thus central to their aesthetic appreciation. This is less the case when it comes to gustatory experiences, since the same bit of food can be consumed by several subjects who can then have the same (or a very similar) experience, at least to some extent, limited by the size/quantity available of the given piece of food. While you cannot proprioceive my body, I can taste a bit of your dinner. The privateness aspect of proprioceptive experiences is thus special and stronger than in the case of gustatory experiences. However, the extent to which gustatory experiences can be similar and shared is very limited when compared to experiences of visual and auditory art, where a great-perhaps in principle unlimited - number of observers can have access to the very same artwork.

We might thus suggest that visual and auditory works of art dominate our normal understanding of what art is precisely because they have a public character-thus, they are more easily shareable and more easily accessible (since, as noted above, the spectator does not need to be the artist). As Monroe (2009, p. 134-135) rightly emphasizes, artworks such as paintings and sculptures also are permanent objects, as opposed to performance arts and, relevantly to our discussion, to proprioceptive or gustatory experiences, and this is one more reason for the former to dominate a standard understanding of what art is, since they are thus easily accessible to many observers. Monroe mentions Hegel as defending what he refers to as the 'Consumption Exclusion Thesis', namely the idea that the fact that food is consumed/destroyed while being appreciated does not allow for its possibility to count as an artwork. Proprioceptive and gustatory experiences are even more impermanent and private than that. But, precisely because they are private, proprioceptive and gustatory artworks might provide a stronger aesthetic experience. As Schrenk points out, "while a well conducted performance of a hyong or kata is a pleasure to watch, it is an even greater joy to perform it oneself", and he adds that, for this reason, in order to enjoy an even stronger experience "sometimes hyongs are a blindfolded exercise 
where the practitioner has to rely entirely on proprioception" (Schrenk 2014, p. 108). Perhaps the point here can be put as the idea that in the case of private artworks, the aesthetic experience is more immediate, and that it is thus related more directly to our emotions and feelings, which are central to aesthetic experience (see criterion (4) from Chap. 1). Indeed, as already mentioned above, the subjective perspective is here more important than the objective perspective, and the privateness of the experience is often put forward as being decisively important: "As it turns out, it's not that interesting to watch somebody climb [The Angler — a climbing route in Joe's Valley].[On a technical route with tiny holds], to somebody watching from outside, it looks... like nothing. Even for an experienced climber, it's pretty boring to watch somebody else climb [The Angler].[...] In this particular climb, all those fascinating internal movements are invisible to the external eye. The aesthetics of movement, here, are for the climber alone" (Nguyen 2017). Thus, on the one hand, private artworks have the 'drawback' of not being shareable as easily as visual and auditory public artworks, but on the other hand, precisely because of this aspect, they provide special, and perhaps stronger, aesthetic experiences.

$\S 3$. In the case of private artworks, there is a lot of inter-subjective variance and instability, since, strictly speaking, any given private work of art is unique. But even private artworks often have publicly accessible recipes. This is quite literally the case when it comes to gustatory artworks, where a recipe would provide the means to create a meal which can then provide a given gustatory experience. The situation is very much the same when it comes to a kata or a choreographed dance, which are repeatable in the sense that the practitioner follows a precise recipe, as well as often the guidance of a more experienced practitioner. (Literally, "kata" means "form" (形)). In the case of climbing, route setters prepare the conditions in which a climber can then enjoy such and such an aesthetic experience. This is not very different from the case of music where-often - a score provides the recipe for a given auditory work of art.

There are then two ways to publicly share private artworks: first, by following the same recipes, and second by inter-subjectively sharing the private aesthetic experiences by describing them verbally. Perhaps, there is a third way. Montero (2006) argues that an observer can genuinely proprioceive the aesthetic features of the movements of someone else (she bases her argument on the way 'mirror neurons' work). Perhaps we can say that there are forms of imaginative empathy where in an indirect and fictional but genuine way an observer can put herself in the situation of the one whom she is observing and — at least in a limited way-imaginatively share her proprioceptive experience. While one cannot feel what it is like to be in a qualitative mental state of somebody else, one can sometimes in a very relevant way empathize and get a good grip on the 'what-it-is-like' qualitative aspects of the experience of the other. We cannot share qualia directly, but we can use empathy and imagination to share them indirectly, even though only in a limited way of course. Climbers can often be seen watching other climbers going through a particularly interesting and hard section of a route and, while standing below and simply watching, they would mimic the movements of the one who is climbing, thus 'sharing' her own experience. 
Kata, climbing routes, and choreographed dances prescribe specific movements and specific proprioceptive experiences. Meals prescribe specific gustatory experiences. In this way, someone can prepare the conditions under which someone else will enjoy a private artwork. In the case of gustatory artworks, the role of the appreciator is rather passive, while in the case of proprioceptive artworks the role of the appreciator is often very much active. We might then suggest that in the case of proprioceptive art, the artist is to be identified with the spectator, while in the case of gustatory art, the artist can be identified with the one who prepared the conditions for a gustatory artwork to arise-say, the chef (who can, of course, be the very same person).

Kendall Walton famously argued for the view that paintings are such that they prescribe specific imaginings (see Walton 1990). He insists on the imaginative faculties of the spectator. In Walton's view, pictures depict by being props in games of make-believe. To understand his point, consider games that children play-in a game, an object can represent another object (say, a cardboard big box can represent a car). In the world of the game, the box represents a car, not just because of its very vague resemblance with something that a child can sit in, but mostly because one has simply decided in an imaginary way that it does represent a car. When it comes to depiction and pictures, Walton then appeals to the notion of 'seeing-in' and he argues that there is an experience made of two elements: perception and imagination, which are mixed together in a phenomenologically complex whole. In Walton's view, imagination permeates the perception of the picture, and this is how we see a given painting as a marked surface, while at the same time we see in the painting whatever the painting depicts. Perceiving and imagining thus are part of a single experience of 'imagining-seeing'. 12

Imagination also plays a role in the appreciation of some gustatory and proprioceptive artworks. Remember how Marc Veyrat uses his meal as a means to prescribe a specific imagining about a walk in the forest. Kata, being imaginary combats involving imaginary adversaries, also quite clearly prescribe very specific imaginings, strongly and explicitly related to the movements the karateka is performing. The prescription is public, while the artwork is private.

\section{References}

Benovsky J (2016) Depiction and imagination. Northern Eur J Philos (Sats) 17(1):61-80

Bocek J et al (2018) Adam ondra hung with sensors. What makes him the world's best climber? online at https://www.irozhlas.cz/sport/ostatni-sporty/czech-climber-adam-ondra-climbing-datasensors_1809140930_jab

Fridland E (2011) The case for proprioception. Phenomenol Cogn Sci 10(4):521-540

Gallagher S (2003) Bodily self-awareness and object perception. Theoria Et Historia Scientarum 7(1):53-68

\footnotetext{
${ }^{12}$ In Benovsky (2016), I argue that photographs also are narrative imagination-triggering media.
} 
Hume D (1757) Of the standard of taste, Essays moral and political. George Routledge and Sons, London, 1894

Karlsen G (2010) The beauty of a climb. In: Schmid SE (ed) Climbing—philosophy for everyone: because it's there. Wiley-Blackwell

Korsmeyer C (1999) Making sense of taste. Food and philosophy. Cornell University Press

Massin O, Monnoyer J-M (2003) Toucher et Proprioception. Voir (Barré) 26:48-73

Monroe D (2009) "Can food be art? The problem of consumption.”. In: Allhoff F, Monroe D (eds) Food and philosophy: eat, think, and be merry. Wiley-Blackwell

Montero B (2006) Proprioception as an aesthetic sense. J Aesthetics Art Criticism 64(2):231-242

Nguyen T (2017) The aesthetics of rock climbing. Philosophers' Mag. online at www.philosophers mag.com/essays/170-the-aesthetics-of-rock-climbing

Nguyen T (forthcoming) Games: agency as art. Oxford University Press

O'Shaughnessy B (1998) Proprioception and the body image. In: Bermudez JL, Marcel AJ, Eilan NM (eds) The body and the self. MIT Press, Cambridge

Schrenk M (2014) Is proprioceptive art possible? In: Priest G, Young D (eds) Philosophy and the martial arts. Routledge, New York, pp 101-116

Scruton R (2009) I drink therefore i am: A philosopher's guide to wine. Continuum

Sibley F (1959) Aesthetic Concepts. Phil Rev 68:421-450

Telfer E (2008) Food as art. In: Neill A, Ridley A (eds) Arguing about art: contemporary philosophical debates, Routledge

Todd C (2010) The philosophy of wine: a case of truth, beauty, and intoxication. Routledge

Walton K (1990) Mimesis as make-believe: on the foundations of the representational arts. Harvard University Press

Open Access This chapter is licensed under the terms of the Creative Commons Attribution 4.0 International License (http://creativecommons.org/licenses/by/4.0/), which permits use, sharing, adaptation, distribution and reproduction in any medium or format, as long as you give appropriate credit to the original author(s) and the source, provide a link to the Creative Commons license and indicate if changes were made.

The images or other third party material in this chapter are included in the chapter's Creative Commons license, unless indicated otherwise in a credit line to the material. If material is not included in the chapter's Creative Commons license and your intended use is not permitted by statutory regulation or exceeds the permitted use, you will need to obtain permission directly from the copyright holder.

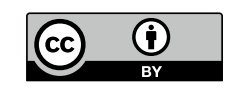

